\title{
Emotional Intelligence and Dentistry
}

\author{
Mohlab Al Sammarraie* \\ University of De La Salle bajio, Mexico \\ *Corresponding Author: Mohlab Al Sammarraie, University of De La Salle bajio, Mexico.
}

Received: June 17, 2019; Published: July 15, 2019

DOI: $10.31080 /$ ASDS.2019.03.0593

American psychologist and science author Daniel Goleman said in his book on Emotional Intelligence, "If you are not able to manage your distressing emotions, if you can't have empathy and have effective relationships, then no matter how smart you are, you are not going to get very far." In dentistry, every activity requires an emotional decision. Effective results in dental practice can only be achieved by employing the use of emotional intelligence. As a dentist with many years of leadership practice, I second these statements and believe that sustainable progress of the profession depends on the ability of all dentists to strike a balance between meeting the emotional needs of the patients and adequately performing the required operational techniques. Although clinical excellence is critical for a successful dental practice, a combination of clinical expertise and emotional intelligence is advised. But what exactly is emotional intelligence?

Emotional intelligence is defined as the capacity for a person to recognize to identify the diverse needs and expectations of people, and own feelings and those of others for effective management of emotions. Emotional intelligence is described by the existence of four dominant behavioral traits, which include self-awareness, social awareness, self-management, and the ability to manage relationships. In employee selection, the profession focuses on the intellectual skills of the individual but also, Emotional intelligence carries more weight relative to IQ in the determination of the individual who succeeds as a leader.

Emotional intelligence is a trait of a competent dentist. Dentists should be aware of their self-emotions and recognize the impact of those emotions in practice. Failure to acknowledge these emotions and manage them appropriately can lead to a projection of these feelings to the patients. For instance, a dentist who is upset about a professional or personal matter and is unable to manage these emotions properly will consequently treat all the patients he or she interacts with while in such emotional state harshly. Identifying the feelings that influence patient interactions and performance is essential for productivity.

Emotional self-control is also essential in dentistry. There are instances when patients reject the recommended treatment plans, employees fail to turn up to work, or the media gives negative comments about the dentist or the institution. In such situations, social awareness is essential. Reactive remarks towards the events can lead to devastating results such as legal suits and compromise on the quality of oral health outcomes. Dentists need to be proactive and tolerant so that they are best placed to address situations amicably and positively.

The ability to persevere and remain motivated through dental practice is a characteristic attribute that depicts emotional intelligence. Dentists must have the drive to keep moving forward even after completing a specific goal. The reason for being a dentist in the first place serves to motivate dentists to continue advancing their standards and quality for an authentic profession. A mix of goals and ideals are driving forces for successful operations in the dental unit. What these assertions imply is that dentists are required to be passionate about their work so that they are motivated to offer the best possible services to their clients. Failure to accept the conditions of the dental industry can be detrimental to the mental health of the dentist resulting in the inability to keep up with changing trends and quality standards.

Dentists interactwith the staffat the medical facility, patients, and personal encounters. Which altogether influences their perception of life and dentistry in general. Given that all these individuals are different with diverse personality traits and health expectations, dentists should be aware of these differences so that they can individualize the relationships for productive encounters. Dentists should be aware of the required boundaries when interacting with people to avoid conflict of interest and confrontations, which may limit their capacity to execute operations.

"Leadership is about influence and inspiration. Influence is about spreading the passion you have for your work, and you have to inspire team-mates and customers." Emotional intelligence is associated with great leadership. Dentists influence the health of their patients, the performance of the organization, including the medical profession. As such, the dentists must be emotionally intelligent by exhibiting qualities such as self-awareness, social awareness, and emotional control.

\section{Volume 3 Issue 8 August 2019}

(C) All rights are reserved by Mohlab Al Sammarraie. 